\title{
EVALUASI KEBERLANJUTAN PERIKANAN GURITA DENGAN INDIKATOR EAFM (ECOSYSTEM APPROACH TO FISHERIES MANAGEMENT) DI KABUPATEN BANGGAI LAUT
}

\author{
Sustainability Assessment of Octopus Fishery with EAFM Indicator \\ in Banggai Laut Regency \\ Oleh: \\ Daniel Julianto Tarigan ${ }^{1 *}$, Domu Simbolon ${ }^{2}$, Budy Wiryawan ${ }^{3}$ \\ 1 Program Studi Teknologi Perikanan Laut, Sekolah Pascasarjana, IPB. danieljuliantoo@gmail.com \\ 2 Program Studi Pemanfaatan Sumberdaya Perikanan, Fakultas Perikanan dan Ilmu Kelautan, Institut Pertanian Bogor. \\ domu@apps.ipb.ac.id \\ 3 Program Studi Pemanfaatan Sumberdaya Perikanan, Fakultas Perikanan dan Ilmu Kelautan, Institut Pertanian Bogor. \\ bud@psp-ipb.org \\ * Korespondensi:danieljuliantoo@gmail.com
}

Diterima: 09 April 2018; Disetujui: 12 Juli 2019

\begin{abstract}
Octopus production data show that catch in Banggai Laut waters is decreasing. In addition, some destructive or illegal fishing gear such as spears, bombs and poisons are still used to catch octopus. Given this alarming situation, this study is intended to assess the sustainability status of octopus fishery in Banggai Laut Regency by means of the Ecosystem Approach Fisheries Management (EAFM) indicator. Octopus catch data incorporating species and amount of catch, number of fishing efforts, mantle size, weight, fishing ground, and the type of protected species are obtained through direct observation on handline fishing and interviews with fishermen. Furthermore, the same method was applied to collect fishing techniques data including fishing efforts, fleet size, crew certification and data on illegal fishing practices. The result shows that the status of octopus resource and the domain of fishing technique in Banggai Laut Regency is in the medium category with a value of 63.33 and 68.75 respectively. Accordingly, the sustainability level of octopus fisheries is in the moderate category with a value of 66.04. Fisheries management related to the fishing practice that is targeting undersize octopus and exceeding the annual quota require further investigation in order to maintain the sustainability level of octopus fisheries.
\end{abstract}

Keywords: Banggai Laut Regency, EAFM, octopus, sustainability level

\section{ABSTRAK}

Informasi tentang produksi menunjukkan bahwa hasil tangkapan gurita di perairan Banggai Laut cenderung menurun. Selain itu, penangkapan gurita masih ada yang menggunakan alat tangkap yang destruktif atau illegal seperti tombak, bom dan racun. Hal ini sangat mengkhawatirkan keberlanjutan sumberdaya gurita. Penelitian ini bertujuan untuk mengevaluasi status atau tingkat keberlanjutan perikanan gurita di Kabupaten Banggai Laut. Kondisi keberlanjutan perikanan gurita di Kabupaten Banggai Laut dianalisis menggunakan indikator Ecosystem Approach Fisheries Management (EAFM). Data sumberdaya gurita diperoleh melalui pengamatan langsung dalam kaitannya dengan pancing ulur dan wawancara yang meliputi jenis dan jumlah produksi hasil tangkapan pancing ulur, upaya penangkapan, ukuran panjang mantel 
gurita, bobot gurita, spot daerah penangkapan gurita dan spesies yang dilindungi. Data teknik penangkapan ikan diperoleh melalui wawancara, survey dan observasi data yang meliputi data upaya penangkapan, jumlah armada penangkapan pancing ulur, sertifikasi awak kapal perikanan dan pelanggaran operasi penangkapan pancing ulur. Domain sumberdaya gurita di Kabupaten Banggai Laut termasuk dalam kategori sedang dengan nilai 63,33. Domain teknik penangkapan termasuk kategori sedang dengan nilai 68,75. Tingkat keberlanjutan perikanan gurita secara keseluruhan termasuk kategori sedang dengan nilai 66,04. Pengelolaan terkait penangkapan gurita yang berukuran tidak layak tangkap dan membatasi hasil tangkapan maksimal yang boleh ditangkap per tahun perlu dilakukan untuk menjaga tingkat keberlanjutan perikanan gurita.

Kata kunci: Kabupaten Binggai Laut, EAFM, gurita, keberlanjutan

\section{PENDAHULUAN}

Gurita merupakan salah satu sumberdaya perikanan yang memiliki nilai ekonomis penting. Nilai ekonomis gurita menjadikannya sebagai salah satu komoditas eksport dari Indonesia. Peningkatan permintaan terhadap sumberdaya gurita menjadikan peluang bagi perikanan di Indonesia. Meningkatnya permintaan pasar terhadap produk gurita dikhawatirkan menyebabkan tekanan terhadap sumberdaya gurita itu sendiri. Tekanan penangkapan yang terus menerus dikhawatirkan mengganggu keberlanjutan sumberdaya gurita.

Data time series tentang perkembangan produksi gurita dewasa ini masih terbatas di Kabupaten Banggai Laut. Informasi tentang produksi menunjukkan bahwa tangkapan gurita di perairan Banggai Laut cenderung menurun setiap tahunnya. Pada tahun 2014, total produksi gurita mencapai 790 ton, namun cenderung menurun tahun 2015 menjadi 409 ton dan hanya 352 ton pada tahun 2016. Selain itu, penangkapan gurita masih ada yang menggunakan alat tangkap yang destruktif dan illegal. Penangkapan dilakukan menggunakan alat tangkap tombak, bom dan racun. Hal ini sangat mengkhawatirkan keberlanjutan sumberdaya gurita. Oleh karena itu, dibutuhkan pengelolaan yang bertujuan untuk menjamin keberlanjutan sumberdaya gurita.

Pengelolaan perikanan merupakan suatu kegiatan yang wajib dilakukan untuk mencapai perikanan yang berkelanjutan. Ecosystem Approach to Fisheries Management (EAFM) merupakan pendekatan pengelolaan dengan konsep bagaimana menyeimbangkan antara tujuan sosial, ekonomi dan kesehatan ekosistem perikanan secara terpadu, komprehensif dan berkelanjutan (FAO 2003). Penelitian pengelolaan dengan pendekatan EAFM sudah banyak yang melakukan (Adel et al. 2016; FAO 2003; Garcia dan Cochrane 2005). Oleh karena itu, dalam kajian pengelolaan sumberdaya perikanan gurita akan dilakukan dengan pendekatan EAFM. Pendekatan EAFM dalam studi ini menggunakan 2 domain/aspek, meliputi aspek/domain sumberdaya gurita dan teknik penangkapan gurita.

Penelitian gurita umumnya masih terkait dengan alat tangkap (Farikha et al. 2014), makanan (FAO 2014; Segawa dan Namoto 2002) dan habitat (Herwig et al. 2012; Raberinary dan Benbow 2012). Penelitian ini bertujuan untuk mengevaluasi status atau tingkat keberlanjutan perikanan gurita di Kabupaten Banggai Laut dengan menggunakan pendekatan EAFM.

\section{METODE}

Penelitian dilaksanakan pada bulan September dan Oktober 2017 di Desa Provinsi dan Banggai, Kabupaten Banggai Laut, Provinsi Sulawesi Tengah. Lokasi penelitian disajikan pada Gambar 1.

Jenis data yang digunakan dalam penelitian ini adalah data primer dan data sekunder. Data primer meliputi domain/aspek sumberdaya gurita dan aspek teknik penangkapan gurita. Data primer diperoleh melalui survei, observasi langsung dan melalui wawancara. Wawancara dilakukan terhadap responden yang berkepentingan dalam pengelolaan gurita di Kabupaten Banggai Laut. Responden ditentukan menggunakan teknik snowball sampling. Menurut Salganik dan Douglas (2007), snowball sampling adalah suatu pendekatan untuk menemukan informan-informan (responden) kunci yang memiliki banyak informasi terkait dengan penelitian yang dilakukan. Pendekatan dilakukan menggunakan beberapa responden yang berkompeten untuk dihubungi dan ditanya apakah narasumber mengetahui responden lain dengan kriteria yang sudah ditentukan sesuai keperluan penelitian. Kontak awal sangat membantu peneliti untuk mendapatkan responden lainnya. Data dikumpulkan melalui wawancara terhadap responden. Wawancara dilaku- 
kan secara terstruktur menggunakan daftar pertanyaan (kuisioner). Walpole (1995) menyebutkan jumlah sampel yang dapat digunakan dalam penelitian sebanyak $10 \%$ dari total sampel yang bersifat homogen. Berdasarkan hal tersebut, jumlah sampel yang digunakan adalah 30 responden yang terdiri dari 20 sampel nelayan dari 104 total nelayan yang ada, 5 sampel pegawai Dinas Kelautan dan Perikanan Kabupaten Banggai Laut, 3 sampel pegawai Badan Karantina ikan, Pengendalian Mutu dan Keamanan Hasil Perikanan dan 2 pegawai Pengawasan Sumberdaya Kelautan dan Perikanan. Data sekunder diperoleh dari Dinas Kelautan dan Perikanan Kabupaten Banggai Laut. Data yang dikumpulkan meliputi data produksi, data jumlah armada perikanan gurita, dan data pelanggaran.

Kondisi keberlanjutan perikanan gurita di Kabupaten Banggai Laut dianalisis menggunakan pendekatan penilaian indikator Ecosystem Approach Fisheries Management (EAFM). Tahapan analisis dengan pendekatan EAFM mengacu pada KKP (2014), Budiarto et al. (2015) dan Pregiwati et al. (2015). Tahapan analisis dengan pendekatan EAFM adalah sebagai berikut KKP (2014), Budiarto et al. (2015) dan Pregiwati et al. (2015):

1. Menentukan kriteria untuk setiap indikator dari masing-masing domain/aspek yang terdapat di dalam EAFM (aspek sumber daya dan teknik penangkapan).

2. Menentukan batasan nilai (reference point) untuk masing-masing kriteria pada setiap indikator.

3. Menentukan bobot untuk setiap indikator. Pembobotan ditetapkan dalam skala 0-100. Indikator yang memiliki bobot besar dianggap memiliki nilai kepentingan paling tinggi dalam domain tersebut. Pembobotan maksimal tiap domain/aspek adalah 100 yang dibagi habis dalam setiap indikator.

4. Mengkaji keragaan masing-masing indikator yang diuji.

5. Menentukan nilai skor untuk setiap indikator dengan menggunakan skala Likert (berbasis ordinal 1 dan 3) sesuai dengan keragaan masing-masing indikator. Penentuan skor 1 dan 3 didasarkan pada data indikator EAFM yang telah dikumpulkan. Data dikumpulkan dengan mempertimbangkan sifat homogen yaitu alat tangkap pancing ulur dan Kabupaten Banggai Laut yang merupakan daerah yang masih dalam tahap pengembangan. Nilai skor digunakan untuk menunjukkan bagus atau jeleknya nilai suatu indikator. Nilai skor indikator dapat dilihat pada Tabel 1.

6. Menentukan nilai dari masing-masing indikator dengan formula:

Nilai Indikator=Bobot $x$ Nilai Skor.

7. Menentukan nilai dari masing-masing aspek/ domain dengan mengakumulasikan nilai indikator yang didapat di dalam setiap aspek.

8. Nilai dari masing-masing domain/aspek kemudian dianalisis dengan menggunakan analisis komposit sederhana berbasis rataan aritmatik. Indeks komposit ini merupakan nilai konversi nilai total setiap aspek/domain EAFM. Proses konversi ini dilakukan untuk memperoleh batasan yang baku dari nilai EAFM. Nilai total dari perkalian komponen EAFM selanjutnya dikonversi dalam skala 33-100. Konversi ini diperlukan untuk memudahkan pengkategorian suatu domain EAFM. Nilai skala setiap domain/aspek yaitu:

Nk-i=(Cat-i)/(Cat-imax) $\times 100$.

dengan:

Cat $\quad$ Nilai total yang didapat dalam
suatu aspek/domain
Cat-imax :
Nilai maksimal dalam suatu
aspek/domain yang diperoleh
saat semua indikator
memiliki skor 3.

9. Menentukan nilai komposit total dari seluruh domain/aspek EAFM yang dikaji. Nilai komposit ditentukan dari nilai rata-rata dari seluruh domain yang dikaji dalam wilayah EAFM. Hasil ini kemudian dikonversi menjadi nilai dengan skala 33-100. Nilai 100 termasuk paling tinggi dan paling baik kondisinya, dan nilai yang rendah tergolong paling buruk kondisinya. Nilai yang didapat kemudian dideskripsikan atas 5 kelompok atau kategori. Kelima kategori ini menggambarkan 5 tingkatan status pengelolaan perikanan suatu wilayah. Kategori nilai EAFM dapat dilihat pada Tabel 2.

Penilaian terhadap aspek/domain sumberdaya gurita meliputi 6 indikator. Indikator tersebut meliputi CPUE, tren ukuran gurita, proporsi ikan juvenile yang ditangkap, komposisi spesies hasil tangkapan, range collapse sumberdaya ikan dan spesies endangered species, threatened species, and protected species (ETP). Kriteria penilaian dan bobot untuk masing-masing indikator disajikan pada Tabel 3. Pemberian bobot untuk masing- 


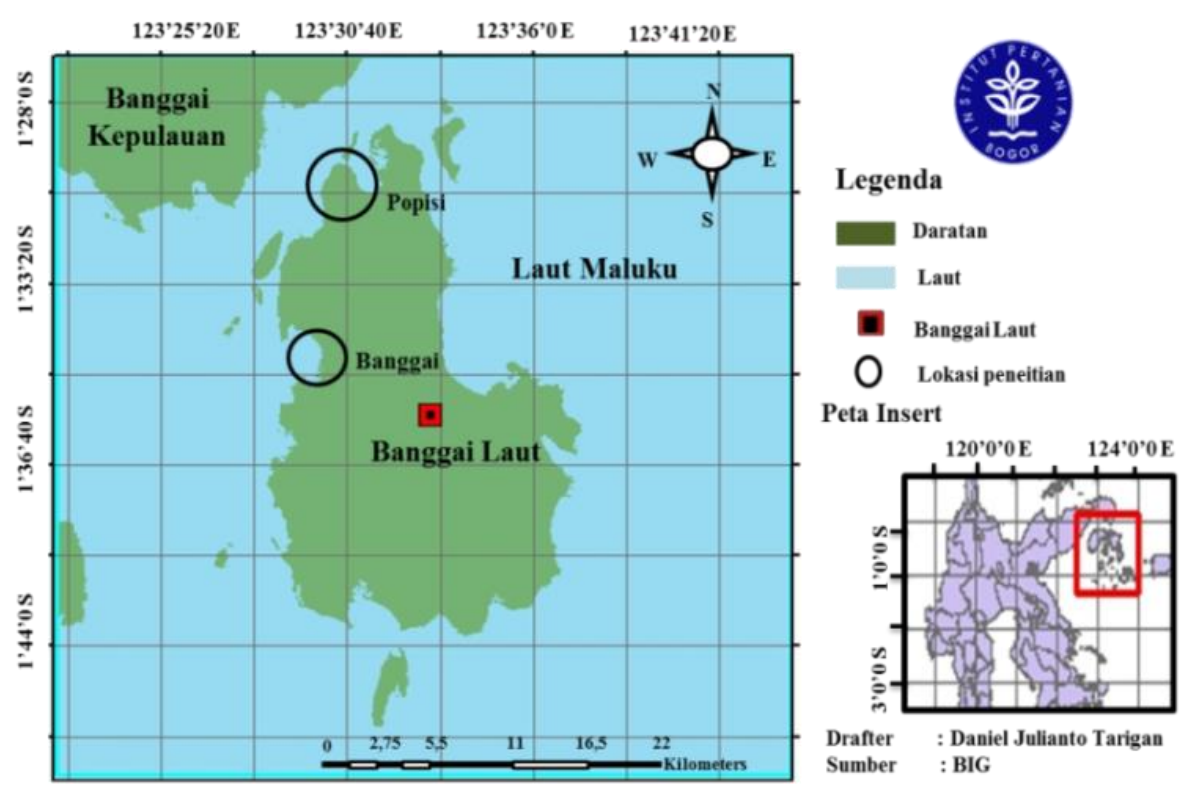

Gambar 1 Peta lokasi penelitian

Tabel 1 Nilai skor indikator

\begin{tabular}{lc}
\hline Skor Indikator & Deskripsi \\
\hline 1 & Jelek/rendah \\
2 & Sedang \\
3 & Baik \\
\hline
\end{tabular}

Sumber: KKP (2014), Budiarto et al. (2015) dan Pregiwati et al. (2015)

Tabel 2 Batasan skor nilai EAFM

\begin{tabular}{|c|c|c|}
\hline \multicolumn{2}{|c|}{ Rentang Nilai } & Deskripsi \\
\hline$\geq 33,33$ & $\leq 46,17$ & Buruk dalam menerapkan EAFM \\
\hline$\geq 46,67$ & $\leq 59,5$ & Kurang dalam menerapkan EAFM \\
\hline$\geq 60$ & $\leq 72,83$ & Sedang dalam menerapkan EAFM \\
\hline$\geq 73,33$ & $\leq 86,17$ & Baik dalam menerapkan EAFM \\
\hline$\geq 86,67$ & $\leq 100$ & Sangat baik dalam menerapkan EAFM \\
\hline
\end{tabular}

masing indikator berbeda-beda. Hal ini didasarkan pada tingkat kepentingan dari indikatorindikator yang ada. Bobot tren ukuran ikan dan proporsi juvenile yang tertangkap merupakan yang terbesar (30). Hal ini menunjukkan bahwa indikator tersebut menjadi indikator yang paling utama dalam aspek/domain sumberdaya gurita. Jika penangkapan dilakukan dengan menangkap ukuran gurita yang kecil, akan menyebabkan menurunnya laju recruitmen (Simbolon 2007). Indikator spesies ETP merupakan yang terkecil (5) yang menunjukkan bahwa indikator tersebut memiliki tingkat kepentingan yang paling kecil dalam penilaian aspek sumberdaya gurita.

Penilaian terhadap CPUE bertujuan untuk mengetahui tren perubahan status stok ikan dari kegiatan perikanan yang diteliti dari waktu ke waktu. Tren CPUE yang menunjukkan kecenderungan menurun dapat mengindikasikan bahwa telah terjadi dampak negatif terhadap stok gurita di suatu wilayah perairan atau kecenderungan mengalami overfishing. Perhitungan CPUE dilakukan dengan rumus sebagai berikut:

$C P U E=\frac{\text { Total produksi pada tahun } k e-i}{\text { Jumlah armada yang beroperasi }}$

Ukuran rata-rata gurita yang tertangkap selama kegiatan penelitian dianalisis secara deskriptif. Hasil analisis kemudian disajikan dalam bentuk tabel atau grafik. Selanjutnya dibandingkan dengan hasil penelitian beberapa tahun terakhir untuk dilihat tren ukuran gurita yang tertangkap. Data tangkapan gurita dari setiap sampel kapal dicatat jumlahnya dan diukur panjang mantel sejumlah 804 sampel gurita. Data gurita dibedakan berdasarkan jenis kelamin jantan dan betina. Perbedaan gurita jantan dan betina terletak pada lengan atau tentakel ketiga. Gurita jantan memiliki garis putih disepanjang tentakel, dengan ujung tentakel berbentuk kerucut. Adapun gurita betina tidak 
memiliki garis putih di tentakel, dengan ujung tentakel berbentuk bulat.

Pengukuran sampel gurita dilakukan dengan mengikuti tahapan berikut: (1) menyortir tangkapan pancing ulur berdasarkan jenis tangkapan dan mencatat jumlah setiap jenis tangkapan, (2) mengambil sampel gurita tanpa mempertimbangkan ukuran gurita yang telah disortir dengan by-catch (3) mengukur panjang mantel gurita dan mencatatnya pada log book yang telah disediakan. Panjang mantel gurita diukur mulai dari ujung kepala hingga bagian titik tengah mata (FAO 2014). Setelah panjang mantel diukur, (4) selanjutnya dilakukan penimbangan bobot gurita, dan kemudian bobot tersebut dicatat pada log book yang telah disediakan.

Indikator proporsi juvenile yang tertangkap digunakan untuk melihat alat tangkap yang digunakan oleh nelayan setempat terhadap proporsi gurita juvenile yang tertangkap. Hasil analisis disajikan dalam bentuk tabel atau grafik kemudian dianalisis secara deskriptif. Semakin banyak proporsi gurita kecil yang tertangkap maka dapat dikatakan bahwa alat tangkap yang digunakan nelayan setempat termasuk alat tangkap yang tidak ramah lingkungan.

Penilaian indikator komposisi spesies hasil tangkapan bertujuan untuk mengetahui komposisi spesies gurita yang menjadi target penangkapan dan ikan non target (by-catch). Penentuan komposisi spesies hasil tangkapan dilakukan secara kuantitatif dengan membuat data komposisi spesies target dan non target secara survey dan monitoring. Hasil analisis kemudian disajikan secara deskriptif dalam bentuk grafik atau diagram.

Penilaian terhadap range collapse dilakukan dengan cara wawancara terhadap nelayan pancing ulur gurita yang beroperasi di daerah Kabupaten Banggai Laut. Nelayan pancing ulur yang dijadikan target adalah nelayan yang telah mengoperasikan pancing ulur gurita lebih dari 10 tahun. Tujuan dari indikator ini adalah untuk melihat dampak yang ditimbulkan terhadap biologi dan ekologi gurita sebagai akibat dari tekanan kegiatan penangkapan yang dilakukan.

Penilaian terhadap spesies yang unik dan dilindungi atau Endangered species, Threatened species, and Protected species

Tabel 3 Kriteria penilaian indikator dalam domain/aspek sumberdaya gurita

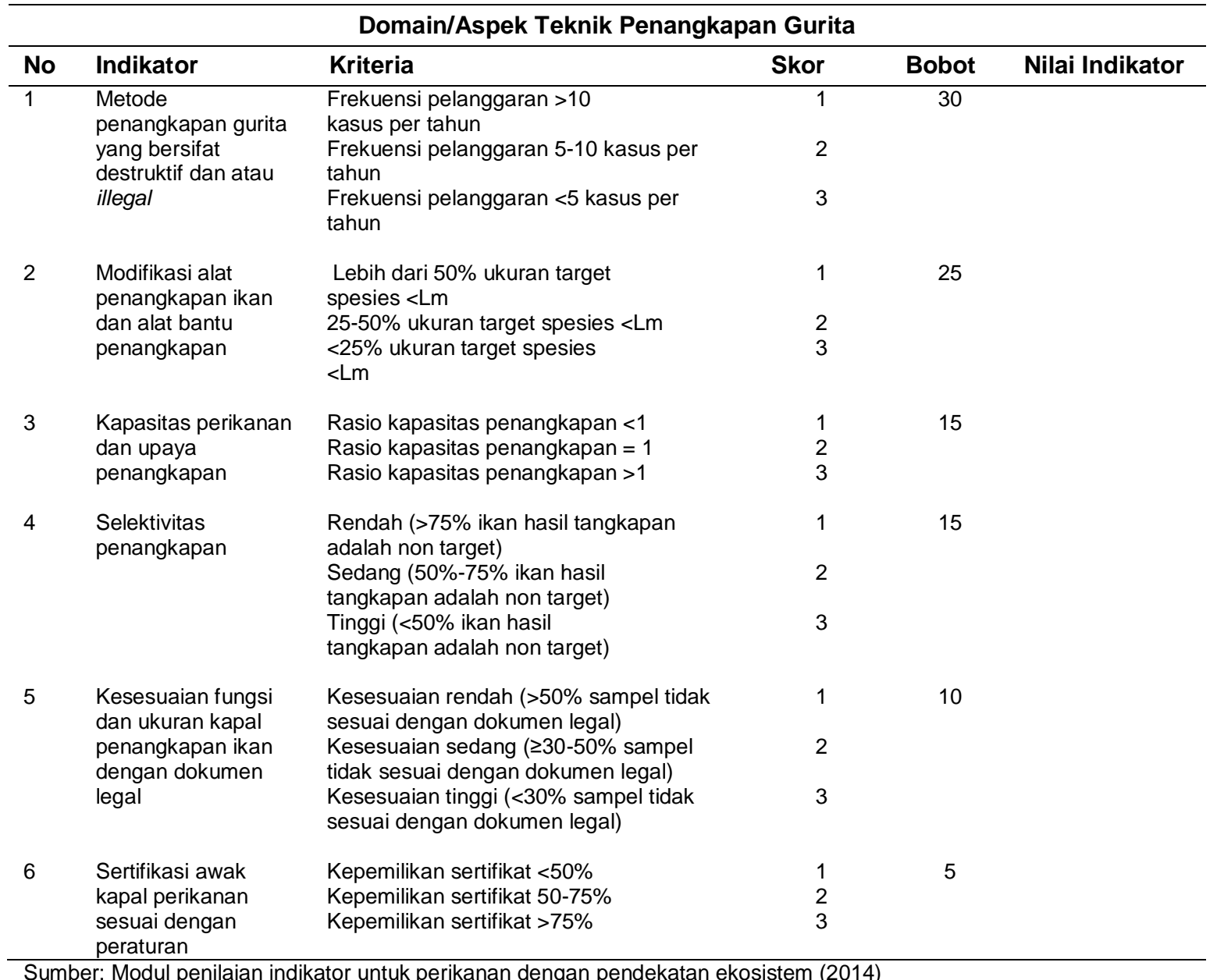


Tabel 4 Kriteria penilaian indikator dalam domain/aspek teknik penangkapan gurita

\begin{tabular}{|c|c|c|c|c|c|}
\hline \multicolumn{6}{|c|}{ Domain/Aspek Sumberdaya Gurita } \\
\hline No & Indikator & Kriteria & Skor & Bobot & Nilai Indikator \\
\hline \multirow[t]{3}{*}{1} & CPUE & $\begin{array}{l}\text { Menurun tajam (rata-rata turun } \\
>25 \% \text { per tahun }\end{array}$ & 1 & 20 & \\
\hline & & $\begin{array}{l}\text { Menurun sedikit (rata-rata turun } \\
<25 \% \text { per tahun) }\end{array}$ & 2 & & \\
\hline & & Stabil/meningkat & 3 & & \\
\hline \multirow[t]{4}{*}{2} & Tren ukuran ikan & Tren ukuran rata-rata semakin & 1 & 30 & \\
\hline & & kecil & 2 & & \\
\hline & & Tren ukuran relatif tetap & 3 & & \\
\hline & & Tren ukuran semakin besar & & & \\
\hline \multirow[t]{3}{*}{3} & Proporsi juvenile & Banyak sekali (>60\%) & 1 & 30 & \\
\hline & yang tertangkap & Banyak $(30-60 \%)$ & 2 & & \\
\hline & & Sedikit $(<30 \%)$ & 3 & & \\
\hline \multirow[t]{3}{*}{4} & $\begin{array}{l}\text { Komposisi spesies } \\
\text { hasil tangkapan }\end{array}$ & $\begin{array}{l}\text { Proporsi target lebih sedikit } \\
\text { ( }<15 \% \text { dari total volume) }\end{array}$ & 1 & 10 & \\
\hline & & $\begin{array}{l}\text { Proporsi target sama dengan } \\
\text { non target }(16-30 \%)\end{array}$ & 2 & & \\
\hline & & $\begin{array}{l}\text { Proporsi target sama dengan } \\
\text { non target }(>31 \%)\end{array}$ & 3 & & \\
\hline \multirow[t]{3}{*}{5} & $\begin{array}{l}\text { Range collapse } \\
\text { sumberdaya ikan }\end{array}$ & $\begin{array}{l}\text { Semakin sulit, tergantung } \\
\text { spesies target }\end{array}$ & 1 & 5 & \\
\hline & & $\begin{array}{l}\text { Relatif tetap, tergantung spesies } \\
\text { target }\end{array}$ & 2 & & \\
\hline & & $\begin{array}{l}\text { Semakin mudah, tergantung } \\
\text { spesies target }\end{array}$ & 3 & & \\
\hline \multirow[t]{3}{*}{6} & Spesies ETP & $\begin{array}{l}\text { Terdapat individu ETP yang } \\
\text { tertangkap namun tidak dilepas }\end{array}$ & 1 & 5 & \\
\hline & & Tertangkap namun dilepas & 2 & & \\
\hline & & $\begin{array}{l}\text { Tidak terdapat individu yang } \\
\text { tertangkap }\end{array}$ & 3 & & \\
\hline
\end{tabular}

Sumber: Modul penilaian indikator untuk perikanan dengan pendekatan ekosistem (2014)

(ETP) dilakukan dengan cara observasi langsung dan wawancara terhadap nelayan dan stakeholder setempat. Hal ini dimaksudkan untuk memperoleh informasi adanya spesies ikan yang unik dan dilindungi yang tertangkap selama dilakukannya operasi penangkapan ikan. Jika banyak spesies yang unik dan dilindungi tertangkap maka kegiatan penangkapan tersebut tidak sustainable.

Penilaian terhadap domain teknik penangkapan ikan meliputi 6 indikator. Indikator tersebut meliputi metode penangkapan ikan yang bersifat destruktif/illegal, modifikasi alat penangkapan ikan, kapasitas perikanan dan upaya penangkapan, selektivitas penangkapan, kesesuaian fungsi dan ukuran kapal, serta sertifikasi awak kapal perikanan. Kriteria penilaian dan bobot untuk masing-masing indikator disajikan pada Tabel 4. Pemberian bobot untuk masing-masing indikator berbeda-beda. Hal ini didasarkan pada tingkat kepentingan dari indikator-indikator yang ada. Penilaian tertinggi terdapat pada aspek/domain metode penangkapan ikan yang bersifat destruktif dan atau illegal yaitu 30. Hal ini dikarenakan bila metode penangkapan ikan dilakukan dengan sifat merusak atau illegal maka akan memberikan tekanan langsung terhadap terjadinya kerusakan sumberdaya dan ekosistem di suatu perairan dalam waktu yang relatif cepat. Nilai terendah terdapat pada indikator sertifikasi awak kapal perikanan yaitu 5 .

Tujuan dari penilaian indikator metode penangkapan ikan yang bersifat destruktif dan atau illegal adalah untuk menilai praktik penangkapan ikan yang bersifat merusak. Penilaian dilakukan dengan memperhatikan jumlah pelanggaran yang dilakukan oleh nelayan terkait dengan penggunaan alat tangkap yang dilarang dalam kurun waktu beberapa tahun. Hasil analisis kemudian disajikan secara deskriptif.

Penilaian terhadap indikator modifikasi alat penangkapan dan alat bantu penangkapan ikan dilakukan dengan cara melakukan sampling terhadap gurita yang tertangkap. Hasil pengukuran tersebut kemudian dibandingkan dengan ukuran gurita pada saat pertama kali matang gonad atau length at first maturity (Lm).

Penilaian terhadap kapasitas perikanan dan upaya penangkapan dianalisis dengan membandingkan jumlah aktivitas penangkapan dalam hal ini adalah jumlah nelayan yang beroperasi. Jumlah nelayan yang dibandingkan adalah jumlah nelayan dalam kurun waktu 3 tahun terakhir mulai dari tahun 2014 hingga tahun 2016.

Selektivitas penangkapan dapat dilihat melalui hasil tangkapan yang diperoleh dari 
penggunaan suatu alat penangkapan ikan. Penilaian terhadap indikator selektivitas alat tangkap dilakukan dengan melihat ukuran gupenggunaan alat tangkap yang digunakan nelayan.

Penilaian terhadap indikator kesesuaian fungsi dan ukuran kapal penangkapan ikan dengan dokumen legal dilakukan dengan melakukan pengecekan langsung. Pengecekan dilakukan untuk mencocokan kesesuaian ukuran dan fungsi kapal dengan dokumen yang ada.

\section{HASIL DAN PEMBAHASAN \\ Status Pengelolaan Perikanan Berdasar- kan Domain Sumberdaya Gurita}

Nilai skor indikator tren ukuran panjang mantel gurita adalah 60 yang berarti relatif tetap. Hasil wawancara terhadap nelayan yang sudah melakukan penangkapan gurita lebih dari 10 tahun menyebutkan tren ukuran gurita yang tetap. Sampling yang dilakukan selama penelitian, terdapat 804 gurita, yakni 495 gurita jantan dan 309 gurita betina.

Panjang mantel gurita jantan berkisar 5,3-18,0 cm dengan rata-rata $11 \mathrm{~cm}$. Hasil tangkapan didominasi ukuran 8-11 cm, yaitu 245 ekor (49\%). Hasil tangkapan sedikit terdapat pada ukuran $16-18 \mathrm{~cm}$ yaitu 18 ekor (4\%) (Gambar 2). Menurut Guard and Mgaya (2002), gurita jantan pertama kali dewasa dengan panjang mantel $7 \mathrm{~cm}$. Oleh karena itu, gurita jantan yang tertangkap di Kabupaten Banggai Laut didominasi oleh ukuran layak tangkap. Jumlah hasil tangkapan yang layak tangkap yaitu 340 ekor (69\%), sedangkan yang tidak layak tangkap 155 ekor (31\%). Berikut merupakan sebaran panjang mantel gurita jantan dan betina (Gambar 2).

Tangkapan gurita betina didominasi panjang mantel 11-13 cm, yaitu 103 ekor (33\%). Adapun hasil tangkapan gurita dengan ukuran $18 \mathrm{~cm}$ sebanyak 2 ekor (1\%). Menurut Guard dan Mgaya (2002), gurita betina pertama kali dewasa dengan ukuran panjang mantel $7,7 \mathrm{~cm}$. Oleh karena itu panjang mantel gurita betina yang tertangkap didominasi ukuran yang layak tangkap. Jumlah hasil tangkapan yang layak tangkap yaitu 211 ekor (68\%), sedangkan yang tidak layak tangkap 98 ekor (32\%). Sebaran panjang mantel jantan dan betina didominasi layak tangkap yaitu 551 ekor (68\%), dan hanya 253 ekor (32\%) yang termasuk tidak layak tangkap.

Nilai skor indikator proporsi gurita juvenile yang tertangkap adalah 60 ekor yang berarti banyak. Pada gurita jantan, bobot tang- rita yang tertangkap dan juga banyaknya spesies ikan non target yang tertangkap dari

kapan berkisar 0,05-4,07 kg dengan rata-rata $1,01 \mathrm{~kg}$. Tangkapan gurita didominasi ukuran 0,07-1,00 kg, yaitu 226 ekor (46\%), sedangkan tangkapan yang berukuran 3,08-4,07 kg hanya 6 ekor (1\%) (Gambar 3). Guard dan Mgaya (2002) menyebutkan bahwa ukuran gurita jantan kategori dewasa adalah 320 gr. Oleh karena itu, gurita jantan yang tertangkap didominasi oleh kategori layak tangkap. Jumlah tangkapan gurita jantan yang termasuk dalam kategori layak tangkap adalah 448 ekor (91\%), dan hanya 47 ekor (9\%) yang masuk dalam kategori tidak layak tangkap.

Bobot tangkapan gurita betina berkisar 0,05-4,02 kg dengan rata-rata $1,00 \mathrm{~kg}$. Tangkapan didominasi ukuran 0,06-0,09 kg, yaitu 108 ekor (35\%), sedangkan tangkapan yang berukuran 3,00-4,00 kg hanya 9 ekor (3\%) (Gambar 3). Guard dan Mgaya (2002) menyebutkan bahwa ukuran gurita betina kategori dewasa adalah 600 gr. Oleh karena itu, gurita betina yang tertangkap di perairan Banggai Laut pada bulan September-Oktober 2017 telah didominasi oleh kategori layak tangkap secara biologis.

Nilai indikator komposisi spesies hasil tangkapan adalah 20. Hal ini mengindikasikan bahwa proporsi spesies target (gurita) mendominasi hasil tangkapan (16-30\%). Penangkapan gurita di Kabupaten Banggai Laut umumnya dilakukan dengan menggunakan pancing ulur. Jumlah total tangkapan pancing ulur di perairan Banggai Laut pada tahun 2016 tercatat 33.088 ton. Jumlah tangkapan terbanyak adalah lencam dan gurita, yaitu 8.076 ton (26\%) dan 8.034 ton (24\%), kemudian menyusul kerapu 7.600 ton (23\%). Berikut merupakan komposisi hasil tangkapan pancing ulur di Kabupaten Banggai Laut (Gambar 4).

Nilai indikator range collapse sumberdaya gurita adalah 10. Hal ini menunjukkan bahwa nelayan menangkap gurita pada lokasi yang tetap. Nelayan sulit menangkap gurita di dekat perairan Banggai Laut, karena menurunnya stok sumberdaya. Sudarmo et al. (2013) menyatakan salah satu faktor yang mempengaruhi nelayan untuk memilih lokasi penangkapan ikan adalah ketersediaan sum-berdaya ikan. Selain itu terbatasnya kemampuan armada penangkapan nelayan dalam menjangkau daerah penangkapan ikan yang lebih jauh.

Nilai indikator spesies Endangered species, Threatened species, and Protected species (ETP) adalah 15. Hasil ini menunjukkan bahwa aktivitas penangkapan gurita yang 
dilakukan nelayan tidak ada spesies ETP yang tertangkap. Berdasarkan informasi nelayan dan pengamatan yang dilakukan selama penelitian tidak ditemukan adanya spesies ETP yang ditangkap. Spesies ETP yang dimaksud antara lain hiu, penyu, lumba-lumba.

Nilai skor indikator CPUE yang diperoleh adalah 20, yang berarti rendah. Hal ini menunjukkan bahwa telah terjadi penurunan CPUE yang tajam (>25\%). Hasil tersebut diperoleh dari perhitungan CPUE pada tahun 2014 hingga tahun 2016. Tahun 2014 terjadi penurunan sebesar $52 \%$ dan pada tahun 2015 terjadi penurunan sebesar $45 \%$. Penilaian komposit domain/aspek sumberdaya gurita terdiri dari 1 indikator bernilai baik, 4 indikator bernilai sedang dan 1 indikator bernilai buruk (Gambar 5). Nilai komposit yang paling mempengaruhi sumberdaya gurita adalah trend CPUE. Hal ini disebabkan karena indikator CPUE yang dalam kondisi buruk. Kondisi buruk tersebut diakibatkan oleh penurunan CPUE. Penurunan CPUE merupakan indikasi terjadinya penurunan stok sumberdaya gurita. Tren penurunan CPUE juga dapat dijadikan indikator bahwa kegiatan penangkapan gurita di daerah Kabupaten Banggai Laut telah terjadi tekanan penangkapan yang berlebihan. Pengelolaan sumberdaya gurita perlu dilakukan dengan cara mengendalikan jumlah upaya penangkapan pada tingkat alokasi optimum (Simbolon et al. 2011; Triono et al. 2015; Nelwan et al. 2010). Selain itu, ukuran gurita yang tertangkap perlu dikontrol mengingat jumlah hasil tangkapan banyak yang berukuran kecil dan sedang. Hal ini seharusnya menjadi perhatian masyarakat dan pemerintah setempat. Bila operasi penangkapan dilakukan secara terus menerus dan dalam jumlah hasil tangkapan yang banyak, bukan tidak mungkin kategori yang sedang pada aspek/domain sumberdaya gurita akan berubah menjadi buruk dalam beberapa tahun mendatang.

Hasil penilaian indikator keseluruhan pada domain/aspek sumberdaya gurita menunjukkan nilai 190. Rata-rata nilai indikator sumberdaya gurita adalah 63,33 dengan kategori sedang (Tabel 5).

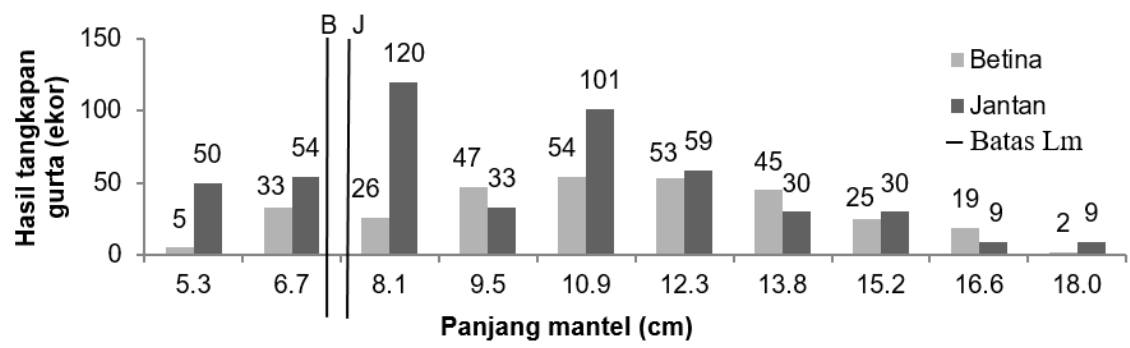

Gambar 2 Sebaran ukuran panjang mantel gurita

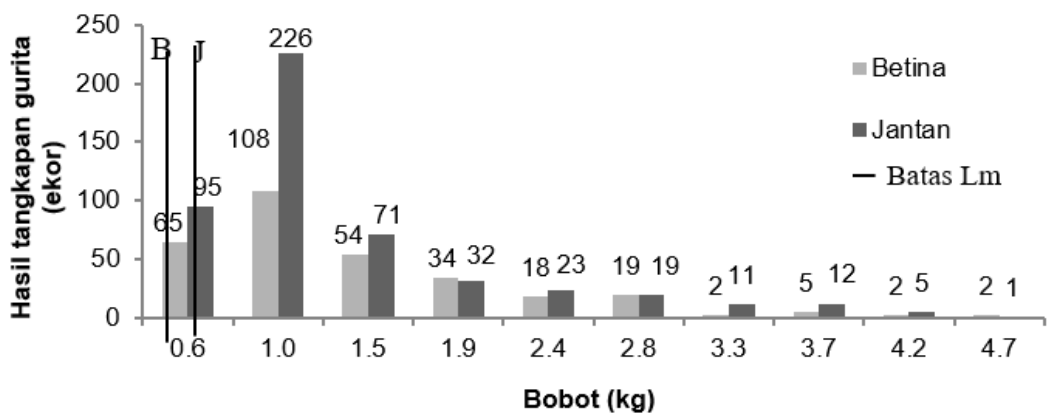

Gambar 3 Sebaran bobot gurita

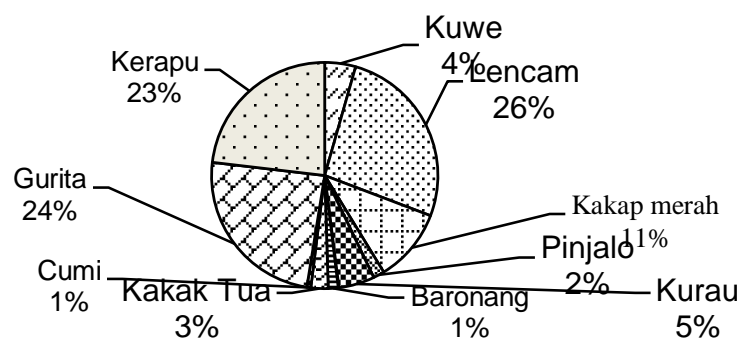

Gambar 4 Komposisi hasil tangkapan pancing ulur di Kabupaten Banggai Laut 


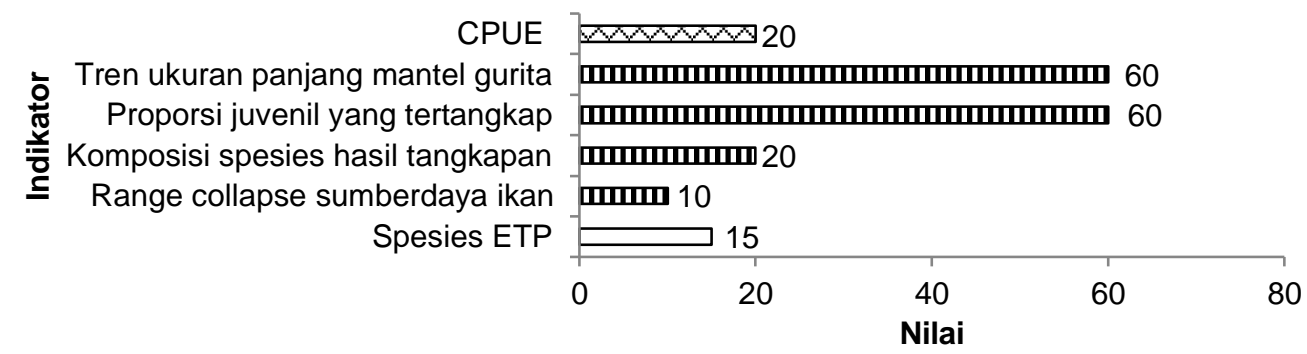

Gambar 5 Perhitungan nilai komposit domain/aspek sumberdaya ikan

\section{Status Pengelolaan Perikanan Berdasar- kan Domain Teknik Penangkapan Gurita}

Nilai indikator metode penangkapan ikan yang bersifat destruktif dan atau illegal adalah 90. Hasil ini menunjukkan bahwa frekuensi pelanggaran yang terjadi kurang dari 5 kasus pertahun. Metode penangkapan ikan yang bersifat destruktif atau illegal dapat secara langsung mengakibatkan kerusakan sumberdaya ikan beserta ekosistem didalamnya. Metode destruktif tersebut meliputi penggunaan bom, racun sianida maupun potassium. Penggunaan alat tangkap yang destruktif ataupun tidak ramah lingkungan juga dapat menimbulkan kerusakan. Penggunaan alat tangkap yang destruktif atau illegal sudah diatur dalam UU No 45/2009 tentang Perikanan pasal 8 ayat 1 sampai 3 dan pasal 12 ayat 1 . Larangan metode penangkapan ikan yang destruktif atau illegal seharusnya sudah ditaati oleh semua pihak.

Nilai indikator modifikasi alat penangkapan dan alat bantu penangkapan ikan 75 , yang berarti baik. Modifikasi alat tangkap pancing ulur yang dilakukan nelayan hanya sebatas penambahan panjang tali pancing dan penggunaan batu, masker dan balok kayu sebagai alat bantu penangkapan. Panjang tali pancing ulur mencapai kedalaman 20-25 m. Penggunaan batu dimaksudkan untuk mempercepat penurunan pancing ulur. Masker selam digunakan untuk mempermudah/melihat di dalam air laut, sehingga dapat lebih mudah menemukan tempat gurita bersembunyi. Alat bantu penangkapan balok kayu digunakan untuk memukul gurita agar mudah dilumpuhkan.

Nilai indikator kapasitas perikanan dan upaya penangkapan adalah 30 . Kapasitas perikanan dan upaya penangkapan yang ada di Kabupaten Banggai Laut menunjukkan rasio kapasitas penangkapan $\leq 1$. Berdasarkan data DKP Banggai Laut, jumlah nelayan gurita yang beroperasi di Kabupaten Banggai Laut dari tahun 2014-2016 menunjukkan peningkatan jumlah nelayan sebanyak 67 nelayan dari tahun 2015 ke 2016.

Nilai indikator selektivitas penangkapan adalah 45 . Hal ini menunjukkan bahwa nelayan
Kabupaten Banggai Laut sebagian besar menggunakan alat tangkap yang ramah lingkungan dalam menangkap gurita. Sebagian besar nelayan menggunakan pancing ulur dalam menangkap gurita. Alat tangkap yang digunakan khusus untuk menangkap gurita, yaitu pancing ulur dengan umpan buatan cipo dan manis. Pancing ulur merupakan salah satu alat penangkapan ikan yang dikategorikan sebagai alat tangkap yang selektif (Sulistyaningsih et al. 2011).

Nilai indikator kesesuaian fungsi dan ukuran kapal penangkapan ikan dengan dokumen legal adalah 30. Hal ini menunjukkan bahwa kesesuaian kapal dengan dokumen yang ada sangat tinggi. Berdasarkan hasil wawancara terhadap pegawai Dinas Kelauan dan Perikanan Kabupaten Banggai Laut lebih dari 90\% (dari total 1818 armada) kapal yang beroperasi di Kabupaten Banggai Laut memiliki kesesuaian fungsi dan ukuran.

Kondisi domain/aspek teknik penangkapan gurita mendapatkan hasil komposit sedang dengan nilai 68,75 (Gambar 6). Teknik penangkapan gurita yang dilakukan nelayan pancing ulur di Kabupaten Banggai Laut sudah ramah lingkungan. Penggunaan alat tangkap pancing ulur dengan umpan buatan (manis dan cipo) dan metode penangkapan yang dipakai oleh nelayan bersifat ramah lingkungan. Hasil tangkapan menunjukkan bahwa gurita yang tertangkap sudah selektif sesuai ukuran yang layak tangkap dan spesies target yang ditangkap.

Sertifikasi awak kapal perikanan termasuk dalam indikator yang buruk dengan nilai 5 . Sertifikasi awak kapal bernilai rendah dikarenakan nelayan yang belum memiliki keahlian khusus untuk penanganan pasca penangkapan gurita. Oleh karena itu diperlukan peningkatan dan pelatihan sertifikasi terkait penanganan pasca penangkapan. Hal ini dilakukan terhadap nelayan untuk meningkatkan kualitas hasil tangkapan gurita, mengingat hasil tangkapan gurita merupakan komoditas ekspor dan juga untuk menjamin bahwa nelayan gurita di Bang-

gai Laut sudah terampil dalam menangkap atau melakukan penanganan hasil pasca tangkapan. Selain itu, yang perlu dipertimbangkan secara 
umum pada domain teknik penangkapan gurita yaitu dengan pembatasan alat tangkap gurita. Hal ini digunakan untuk menjamin keberlanjutan sumberdaya gurita dari penggunaan alat tangkap yang berlebihan (Fernandez \& Rueda 2007, Kim 2008, Sudarmo et al. 2016).

Hasil penilaian indikator keseluruhan pada domain/aspek teknik penangkapan gurita menunjukkan nilai 275. Rata-rata nilai indikator domain/aspek teknik penangkapan gurita adalah 68,75 dengan kategori sedang (Tabel 6).

\section{Status Pengelolaan Perikanan Gurita}

Keberlanjutan aspek sumberdaya gurita termasuk dalam kategori sedang dengan nilai 63,33 . Domain/aspek teknik penangkapan gurita juga termasuk kategori sedang, dengan nilai
68,75 . Secara keseluruhan, tingkat keberlanjutan perikanan gurita di Kabupaten Banggai Laut diperoleh hasil sedang, dengan nilai 66,04 (Tabel 7). Kategori sedang, menunjukkan bahwa tingkat keberlanjutan masih memiliki nilai indikator yang kurang baik. Nilai indikator yang kurang baik, menunjukkan bahwa sudah seharusnya perlu dilakukan pengelolaan yang tepat. Pengelolaan dilakukan terhadap nelayan gurita agar tidak melakukan penangkapan gurita yang berukuran tidak layak tangkap dan berlebih. Pengelolaan juga dilakukan terkait batas maksimal hasil tangkapan gurita yang boleh ditangkap per tahun. Selain itu diperlukan penelitian dengan menggunakan domain/aspek lainnya dalam pengelolaan gurita di Kabupaten Banggai Laut. Hal ini diperlukan untuk menjaga keberlanjutan sumberdaya gurita di Kabupaten Banggai Laut.

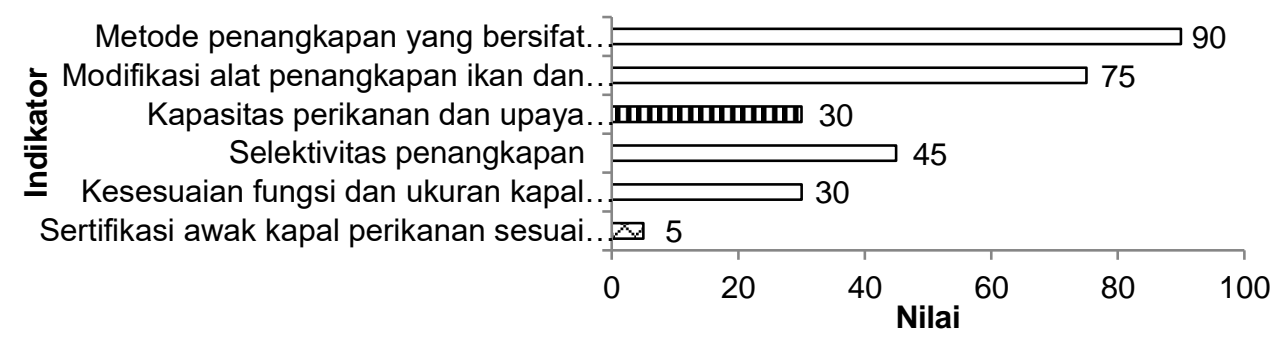

Gambar 6 Perhitungan nilai komposit domain/aspek teknik penangkapan gurita

Tabel 6 Domain/aspek teknik penangkapan gurita

\begin{tabular}{|c|c|c|c|c|}
\hline Indikator & Hasil & Skor & Bobot & Nilai Indikator \\
\hline \multirow[t]{2}{*}{$\begin{array}{l}\text { Metode penangkapan gurita } \\
\text { yang bersifat destruktif atau } \\
\text { illegal }\end{array}$} & $\begin{array}{l}\text { Frekuensi } \\
\text { pelanggaran }<5 \\
\text { kasus pertahun }\end{array}$ & 3 & 30 & 90 \\
\hline & $\begin{array}{l}25-50 \% \text { ukuran } \\
\text { target spesies <Lm }\end{array}$ & 3 & 25 & 75 \\
\hline \multirow{3}{*}{$\begin{array}{l}\text { Modifikasi alat penangkapan } \\
\text { ikan dan alat bantu } \\
\text { penangkapan } \\
\text { Kapasitas perikanan dan upaya } \\
\text { perikanan } \\
\text { Selektivitas penangkapan }\end{array}$} & $\begin{array}{l}\text { Rasio kapasitas } \\
\text { penangkapan }=1\end{array}$ & 2 & 15 & 30 \\
\hline & $\begin{array}{l}\text { Tinggi }(<50 \% \text { ikan } \\
\text { hasil tangkapan } \\
\text { adalah non target })\end{array}$ & 3 & 15 & 45 \\
\hline & $\begin{array}{l}\text { Kesesuian tinggi } \\
(<30 \% \text { sampel tidak }\end{array}$ & 3 & 10 & 30 \\
\hline \multirow{2}{*}{$\begin{array}{l}\text { Kesesuaian fungsi dan ukuran } \\
\text { kapal penangkapan dengan } \\
\text { dokumen legal }\end{array}$} & $\begin{array}{l}\text { sesuai dengan } \\
\text { dokumen legal) }\end{array}$ & & & \\
\hline & $\begin{array}{l}\text { Kepemilikan } \\
\text { sertifikat } 50-75 \%\end{array}$ & 1 & 5 & 5 \\
\hline \multicolumn{5}{|l|}{$\begin{array}{l}\text { Sertifikasi awak kapal perikanan } \\
\text { sesuai dengan peraturan }\end{array}$} \\
\hline \multicolumn{3}{|c|}{ Total Nilai } & & 275 \\
\hline \multicolumn{3}{|c|}{ Nilai Domain } & & 68,75 \\
\hline
\end{tabular}

Tabel 7 Nilai setiap domain/aspek EAFM di Kabupaten Banggai Laut

\begin{tabular}{lcc}
\hline Domain/aspek & Nilai Domain & Keterangan \\
\hline Sumberdaya gurita & 63,33 & Sedang \\
Teknik penangkapan gurita & 68,75 & Sedang \\
\hline Rata-rata agregat & 66,04 & Sedang \\
\hline
\end{tabular}




\section{KESIMPULAN}

Tingkat keberlanjutan pengelolaan perikanan gurita pada domain/aspek sumberdaya gurita dan teknik penangkapan gurita di Kabupaten Banggai Laut tergolong sedang dengan nilai 66,04 .

\section{SARAN}

Perlunya pelatihan dan pemberdayaan nelayan terkait penanganan pasca penangkapan gurita untuk meningkatkan kualitas hasil tangkapan gurita di Kabupaten Banggai Laut.

\section{UCAPAN TERIMA KASIH}

Penulis menyampaikan terima kasih kepada Fakultas Pertanian Universitas Tanjungpura yang telah memberikan pendanaan penelitian DIPA tahun 2017 serta kepada tim redaksi dan reviewer yang telah memberikan saran dan masukan untuk peningkatan kualitas artikel ini.

\section{DAFTAR PUSTAKA}

Adel Y, Yonvitner, Rahardjo MF. 2016. Pengelolaan Sumber Daya Perikanan Banggai Cardinalfish (Pterapogon kauderni, Koumans 1933) dengan Pendekatan Ekosistem (Studi Kasus Pulau Banggai Kabupaten Banggai Laut). Jurnal Ilmu Pertanian Indonesia (JIPI). 21(3): 186-194.

Budiarto A, Adrianto L, Kamal M. 2015. Status Pengelolaan Perikanan Rajungan (Potunus pelagicus) dengan Pendekatan Ekosistem di Laut Jawa (WPPNRI 712). Jurnal Kebijakan Perikanan Indonesia. 7(1): 9-24.

FAO. 2003. The Ecosystem Approach to Fisheries. FAO Technical Guidelines for Responsible Fisheries, 4.

FAO. 2014. Cephalopods of the world. An annotated and illustrated catalogue of cephalopod species known to date. Volume 3. Octopods and Vampire Squids. Species Catalogue for Fishery Purposes. No. 4, Vol. 3. Rome, FAO. 2014. 370 p. 11 colour plates.

Farikha K, Pramonowibowo, Arisyanto. 2014. Pengaruh Perbedaan Bentuk dan Warna Umpan Tiruan terhadap Hasil Tangkapan Gurita pada Alat Tangkap Pancing Ulur di Perairan Baron, Gunung Kidul. Journal of Fisheries Resources Utilization Management and Technology. 3(3): 275-283.
Fernandez, Rueda P. 2007. Octopus vulgaris (Mollusca: Cephalopoda) Fishery Management Assessment in Asturias (NorthWest Spain). Fisheries Research. 83(2 -3): 351-354.

Garcia M, Cochrane KL. 2005. Ecosystem Approach to Fisheries: A Review of Implementation Guidelines. ICES J. Mar. Sci. 62:311-318.

Guard M, Mgaya YD. 2002. The Artisanal Fishery for Octopus cyanea Gray in Tanzania. AMBIO: A Journal of the Human Environment. 31(7): 528-536.

Herwig JN, Depczynski M, Roberts JD, Semmens JM, Gagliano M. 2012. Using Age Based Life History Data to Investigate the Life Cycle and Vulnerability of Octopus cyanea. Plos One. 7(8): 43679.

Kim DH. 2008. Optimal Economic Fishing Efforts in Korean Common Octopus, Octopus Minor Trap Fishery. Fisheries Science. 74(6): 1215-1221.

[KKP] Kementerian Kelautan dan Perikanan. 2014. Indikator untuk Pengelolaan Perikanan dengan Pendekatan Ekosistem (Ecosystem Approach to Fisheries Management). Satker Pengelolaan dan Rehabilitasi Terumbu Karang-CTI. Jakarta.

Nelwan AFP, Sondita MFA, Monintja DR, Simbolon D. 2010. Analisis Upaya Penangkapan Ikan Pelagis Kecil di Selat Makassar, Perairan Pantai Barat Sulawesi Selatan. Jurnal Teknologi Perikanan dan Kelautan. 10(1): 1-14.

Pregiwati LA, Wiryawan B, Baskoro MS, Wisudo SH, Satria A. 2015. Linking Indicators for Ecosystem Approach Fisheries Management and Management of Marine Protected Area Effectiveness in Anambas Island, Indonesia. Aquaculture, Aquarium, Conservation \& Leglislation International Journal of the Bioflux Soceity. 8(6): 1048-1063.

Raberinary D, Benbow S. 2012. The Reproductive Cycle of Octopus cyanea in Southwest Madagascar and Implications for Fisheries Management. Fisheries Research. 125-126: 190-197.

Salganik MJ, Douglas DH. 2007. Sampling and Estimation in Hiden Populations Using Respondent-Driven Sampling. Journal Sociological Methodology, 34(1): 193239.

Segawa S, NomotoA. 2002. Laboratory Growth, Feeding, Oxygen Consumption and 
Ammonia Excretion of Octopus ocellatus. Bulletin of Marine Science. 71: 801-813.

Simbolon D. 2007. Pendugaan Daerah Penangkapan Ikan Tongkol Berdasarkan Pendekatan Suhu Permukaan Laut Deteksi Satelit, dan hasil Tangkapan di Perairan Teluk Palabuharatu. Jurnal Litbangda NTT Kupang. 04: 23-30.

Simbolon D, Wiryawan B, Wahyuningrum PI, Wahyudi H. 2011. Tingkat Pemanfaatan dan Pola Musim Penangkapan Ikan Lemuru di Perairan Selat Bali. Buletin PSP FPIK IPB. 19(3): 295-309.

Sudarmo AP, Baskoro MS, Wiryawan B, Wiyono ES, Monintja DR. 2016. Analisis Internal dan Eksternal Pengelolaan Perikanan Pantai Skala Kecil di Kota Tegal. Marine Fisheries. 7(1): 45-56.
Sudarmo AP, Baskoro MS, Wiryawan B, Wiyono ES, Monintja DR. 2013. Perikanan Skala Kecil: Proses Pengambilan Keputusan Nelayan dalam Kaitannya dengan Fakor-Faktor yang Mempengaruhi $\mathrm{Pe}-$ nangkapan Ikan. Marine Fisheries. 4(2): 195-200.

Sulistyaningsih RK, Barata A, Siregar K. 2011. Perikanan Pancing Ulur Tuna di Kedonganan, Bali. Jurnal Penelitian Perikanan Indonesia. 17(3): 185-191.

Triono, Pangesti P, Wiyono ES, Baskoro M, Nurani TW, Wiryawan B. 2015. Status Bio-ekonomi Sumberdaya Udang di Kabupaten Cilacap. Jurnal Sosial Ekonomi Kelautan dan Perikanan. 10(2): 149-157.

Walpole, RE. 1995. Pengantar Statistik Edisi 3 Alih Bahasa: Bambang Sumantri, Jakarta (ID). Gramedia Pustaka Utama. 518 hal. 